\title{
EXTRAÇÃO E QUANTIFICAÇÃO DAS CLOROFILAS $A$ E B NAS FOLHAS DA XANTHOSOMA SAGITTIFOLIUM
}

\author{
Gabriela Coelho Couceiro' \\ Yara Barbosa Bustamante ${ }^{2}$ \\ Janicy Arantes Carvalho ${ }^{3}$ \\ Diego Pachelli Teixeira ${ }^{4}$ \\ Patrícia Marcondes dos Santos ${ }^{5}$ \\ Milton Beltrame Junior ${ }^{6}$ \\ Andreza Ribeiro Simioni ${ }^{7}$
}

Resumo: A planta Xanthosoma sagittifolium (taioba) é uma hortaliça que pode suprir muitas necessidades, sendo uma fonte de proteínas, cálcio, ferro, vitamina $C$ e outros nutrientes. As clorofilas são os pigmentos mais abundantes nas plantas e possuem vários benefícios à saúde. Sendo assim, foi analisada a presença das clorofilas na espécie Xanthosoma sagittifolium devido ao seu papel na alimentação e seus benefícios à saúde. A concentração das clorofilas a e b foram determinadas por espectrofotometria UV-visível (Cla = $315,43 \mu \mathrm{g} / \mathrm{mL}$ e $\mathrm{Cl} b=62,79 \mu \mathrm{g} / \mathrm{mL}$ ) e a relação de $\mathrm{mg}$ de clorofila por grama de planta foi 2,84 $\mathrm{mg} / \mathrm{g}$ para a clorofila a e $0,57 \mathrm{mg} / \mathrm{g}$ para a clorofila $b$. A partir da análise dos pigmentos obtidos na separação cromatográfica, pode-se comprovar a presença de ambas as clorofilas na planta.

Palavras-chave: Clorofilas; Xanthosoma sagittifolium; Cromatografia.

\footnotetext{
1 Universidade do Vale do Paraíba, E-mail: gabi_couceiro@hotmail.com.

2 Universidade do Vale do Paraíba, E-mail: yara_bustamante@hotmail.com.

${ }^{3}$ Universidade do Vale do Paraíba, E-mail: janicyjun@gmail.com.

4 Universidade do Vale do Paraíba, E-mail: d13teixeira@hotmail.com.

5 Universidade do Vale do Paraíba, E-mail: patriciams@univap.br.

6 Universidade do Vale do Paraíba, E-mail: beltrame@univap.br.

7 Universidade do Vale do Paraíba, E-mail: simioni@univap.br.
} 